\title{
Institutional Model of Development of Formula- Feed Mini-Enterprises in the Russian Federation
}

\author{
Savostin D.S.* \\ Moscow City Teacher Training University \\ Moscow, Russia \\ Magomedov M.D. \\ Moscow City Teacher Training University \\ Moscow, Russia \\ e-mail: profmagomedov@mail.ru
}

\author{
Stroev V.V. \\ Moscow City Teacher Training University \\ Moscow, Russia \\ Karabanova O.V \\ Moscow City Teacher Training University \\ Moscow, Russia
}

\author{
Kulomzina E.Yu. \\ Moscow City Teacher Training University \\ Moscow, Russia
}

\begin{abstract}
The article assesses the state of milk and meat production in Russia. The authors show the current state of mixed feed production in the country. The advantages of formula-feed mini-enterprises are considered. The authors propose the main directions of increasing the efficiency of formula-feed mini-enterprises. There are the methods of system analysis, synthesis, statistical research of market conditions, economic modeling and formalization used to substantiate the conclusions. The study is based on the materials of the State Statistics Service of the Russian Federation, fundamental and applied research by Russian scientists in connection with the specifics of the subject of the study - the development of formulafeed mini-enterprises in Russia.
\end{abstract}

Keywords - institutional model, formula-feed mini-enterprises, milk and meat production.

\section{INTRODUCTION}

Currently, the public pays great attention to the development of small and medium-sized businesses. They are rapidly changing the country's economy for the better. These enterprises receive the substantial support from the state in the developed countries of the world. This subsequently increases their gross domestic product (GDP). Thus, the share of small and medium-sized businesses in their GDP exceeds 50 per cent. While in the Russian Federation, it is only 21 per cent.

\section{PROBLEM STATEMENT}

The results of the analysis of the agro-industrial complex of the Russian Federation have showed that there is a shortage of milk and beef in the country. In order to solve this problem, it is necessary, first of all, to produce a sufficient amount of mixed feeds.

\section{STUDY MATERIALS}

The study is based on the materials of the State Statistics Service of the Russian Federation, fundamental and applied research by Russian scientists in connection with the specifics of the subject of the study - the development of formula-feed mini-enterprises in Russia.

According to data provided by Rosstat (Russian Statistic Service), the production of mixed feeds in the Russian Federation is steadily growing. Despite this positive trend, there is a need for them. In addition, the number of produced mixed feeds for cattle over the past ten years remained at approximately the same level. This negatively affected the elimination of the shortage of the above mentioned livestock products.

\section{DISCUSSION}

The formula-feed plants currently operating, as a rule, have large capacities. The level of their use remains low due to the excessively high transport costs associated with the remoteness of consumers of mixed feed and raw material suppliers. As a result, consumers are forced to feed animals with pure grain instead of mixed feed. This leads to an overrun of feed grain per unit of livestock production. Entrepreneurs engaged in the production of mixed feeds seek to build their small-capacity enterprises (formula-feed mini-enterprises) and place them where there are consumers and suppliers of raw materials. This is beneficial from an economic point of view in most cases. Formula-feed mini-enterprises (small and medium-sized businesses) have clear advantages under market economy conditions. These include:

\section{A. Rapid response to changing market conditions}

This advantage is due to the fact that formula-feed minienterprises quickly adapt to changing market conditions. It is easier for them to adapt to the changing demand of consumers and accordingly change the strategy and tactics of doing business

\section{B. The ability to ensure high competitiveness}

Formula-feed mini-enterprises are able to quickly change their pricing policy and, if necessary, promptly make 
adjustments to the quality of their products. They affect the growth of their competitiveness.

\section{Reduction of unemployment}

The increase in the number of formula-feed minienterprises and especially in rural areas creates additional jobs, which leads to a decrease in unemployment.

\section{Effective use of innovation}

Formula-feed mini-enterprises face great competition and, accordingly, are forced to introduce innovations. They carry it out in strict accordance with economic feasibility. This is primarily due to the limited financial resources.

Formula-feed mini-enterprises are placed, as a rule, on livestock farms and independently. In the first case, formulafeed mini-enterprises fully serves livestock farms, and in the second case, individual farms and farmsteads that keep animals (cows, pigs, poultry, etc.) at home in the countryside. In each case, there are certain features associated with the production and sale of mixed feed. In the production of mixed feeds on formula-feed mini-enterprises that are part of livestock farms, their quantity depends on the volumes of the demand for livestock products, as they are aimed at satisfying domestic needs. In cases where mixed feeds are produced at independent formula-feed mini-enterprises, their quantity must meet the needs and transportation costs of delivering raw materials in an economically reasonable radius.

According to the results of the research, we are recommended to be guided by the following main directions of increasing the efficiency of formula-feed mini-enterprises:

1. Improvement of the quality of the results of marketing research.

2. Implementation of an effective pricing policy.

3. Production of mixed feeds of the optimal range in accordance with the quality requirements.

4. Reduction of the cost of feeds produced.

5. Improvement of economic incentives for workers in formula-feed mini-enterprises.

Let us consider each direction separately.

1. Improvement of the quality of the results of marketing research.

Conducting marketing research under market economy conditions is the cornerstone necessary for the effective development of any enterprise. They must be carried out continuously. This is due to the fact that the demand and supply of products and services rendered on the market change over a short period. Overproduction of products by enterprises leads to an increase in storage costs. With long-term storage of mixed feeds, their quality is reduced under the influence of biological processes. This is because the ingredients included in mixed feeds are oxidized for a short period, and an increase in their shelf life may aggravate the situation. To prevent such negative moments, it is necessary, first of all, to have reliable information about the market situation and then make specific decisions on the volume of feed production. Information can be obtained only by continuous marketing research.
The main type of raw materials necessary for the production of mixed feed is feed grain the proportion of which exceeds $70 \%$. Therefore, it is necessary to pay special attention to the purchase of feed grain. There are a large number of supplies for it on the market, and the question arises what types of grain to buy? To answer this question, it is necessary to know the types and number of mixed feeds, which consumers wish to buy for a given period of time and in the future. According to the results of the research, we propose the following method for determining the optimal variant of the types of grain to be purchased for the production of mixed feed at formula-feed mini-enterprises:

1. To determine the need for the types of mixed feeds for both the livestock complex and other consumers.

2. To compare the need for mixed feeds with the production capacity of the formula-feed mini-enterprise. When they match each other, to consider proposals for the types of grain, taking into account the available non-grain ingredients.

3. Mixed feed must meet the requirements related to the energy value, the content of raw and digestible protein, and crude fiber. To ensure them, it is necessary, taking into account the availability or possibility of purchasing non-grain ingredients, to select such types of grain that meet the specified conditions at the lowest price.

4. In the absence of sufficient capacity of the formula-feed mini-enterprise, to find the opportunities for increasing it. In the absence of own financial resources, to borrow it or to attract the investors. Before making a decision on attracting financial resources, to catty out a detailed economic calculation for each possible option and choose the most profitable one.

Effective sales of manufactured products are the main task of any enterprise. When selling mixed feed, we should comply with the following conditions:

- It is necessary to have reliable information: what types of mixed feeds and in what quantity the consumer need.

- The quality of mixed feeds must strictly comply with the requirements imposed by the buyer.

- Prices for mixed feed must be set acceptable for the buyer and seller.

- The time of delivery of feeds to the consumer or export by them should be fully coordinated.

- Payment by the buyer for received feeds must be carried out in a timely manner according to an agreed schedule.

- To conduct an effective pricing policy.

Prices for mixed feed are set at the formula-feed minienterprise, taking into account the cost of their production and market conditions. Supply and demand for mixed feeds change under the influence of various factors. In a period of declining demand for feed, we should provide discounts on their prices. The value of the price discount should depend on the level of reduction in demand for products, but without a 
significant reduction in profits. Some decrease in profits should be compensated by increasing the volume of sales.

Based on the results of our studies, we recommend that we determine the allowable discount for the following inequality:

$$
D \leq E c e+\Delta E s+\Delta T \cdot I
$$

where $\mathrm{D}$ is the allowable discount per one ton of feed, rubles.

$\Delta E c e$ - saving of commercial expenses per ton of feed, rubles.

$\Delta E s$ - savings in storage per one ton of feed, rubles.

$\Delta T$ - time saved as a result of accelerated payment, days.

$I$ - the amount of bank interest per day.

Practical testing of this inequality at a number of formulafeed mini-enterprises confirmed its validity.

3. Production of mixed feeds of the optimal range in accordance with the quality requirements.

To improve the competitiveness of the enterprise, the production of high quality products is of particular importance. At present, a large variety of products is produced at formula-feed mini-enterprises. They are divided into three main groups - crumbled, granulated and briquetted. All of them are united by the fact that they are made from a large number of ingredients. Granulated and briquetted feeds are more labor intensive to produce in relation to crumbled, but they are of high quality and easier to store.

Crumbled feeds during loading and unloading stratify depending on the proportion of ingredients, as a result of their quality deteriorates. In such conditions, it is necessary to maximize the production of granulated and briquetted feeds. To maintain high quality, all types of feeds must be produced in strict accordance with science-based recipes. In addition, they need to be stored in full compliance with all requirements and should not be delayed. Violation of these provisions leads to the occurrence of undesirable biological processes.

Demand and supply of feed types vary depending on market conditions. In such conditions, the optimization of their range, taking into account all factors, is extremely necessary for each formula-feed enterprise.

\section{Reduction of the cost of feeds produced.}

During the improvement of the competitiveness of a minifeed mill in addition to the quality of products, its price occupies an important place. To conduct an effective pricing policy, it is necessary to reduce the cost of production as much as possible. At the formula-feed enterprises, a significant impact on the cost of production is exerted by raw materials and transportation costs. For the production of mixed feed a large variety of raw materials are used. The main of them is grain and it takes 70 per cent in their total structure. Therefore, formula-feed enterprises tend to the places of grain production. Other ingredients in the absence in the location of formula-feed enterprises have to be imported from the nearest regions of the country.
Significant impact on the cost of production of formulafeed enterprises have losses in the production process. The rules for the introduction of the technological process in formula-feed enterprises include losses of up to one percent. However, the analysis has showed that losses vary widely, from 0.5 per cent to 3 per cent. Therefore, measures should be taken to reduce them.

The important direction to reduce the cost of production of formula-feed enterprises is to reduce transportation costs for the transportation of raw materials and finished products. They should not lead to a deterioration in the financial condition of the company. With changing market factors, a preliminary calculation of transportation costs in each case is necessary before making a management decision.

5. The improvement of economic incentives for workers in formula-feed mini-enterprises.

Increasing the interest of workers in achieving high-end results of formula-feed enterprises is of great importance.

\section{V.CONCLUSION}

When solving this problem, the following conditions should be considered:

1. The average wage of employees should correspond to the level of the market of the region.

2. The distribution of additional incentives between employees should be made depending on the labor participation of each of them.

\section{References}

[1] A.I. Altukhov, Problems of development of the state's agro-industrial complex and the need for their accelerated solution", Econ. of agricult. of Russ., no. 4, pp. 2-14, 2018.

[2] A.I. Altukhov, "Food Security and Independence: Essence and Features", pp. 16-312018 [Mater. of an Int. Sci. Conf. Investment Management and State Investment Policy-2]. Moscow: VNIIESKH.

[3] I.P. Bogomolova, E.I. Krivenko, E.S. Striapikh, T.V. Shevaldova, "Innovative development as an effective organization strategy", Bull. of the Voronezh State Univer. of Engineer. Technol., vol. 80, no. 1(75), pp. 398-412, 2018.

[4] O.V. Karabanova, "Modern problems of import substitution in Russia", Econ. and Entrepreneurship, vol. 9-2, no. 62, pp. 164-166, 2015.

[5] E.Yu. Kulomzina, M.D. Magomedov, E.Yu. Aleksecheva, "Status and development prospects of small and medium-sized businesses in Russia", Econ. and Entrepreneurship, vol. 11-2, no. 76, pp. 399-408, 2016.

[6] M.D. Magomedov, E.Yu. Alekseicheva, E.Yu. Kulomzina, "Economic efficiency improving of the usage of feed grain in the Russian Federation", Econ. and Entrepreneurship, vol. 10-1, no. 63, pp. 580-582, 2015.

[7] O.V. Murashov The efficient development of mill enterprises, Monograph. Moscow: Publ. house "Dashkov and K", 2014.

[8] Yu.I. Popova, M. Magomedov, "Prospects for the development of minibakeries in the Russian Federation", Econ.: yesterday, today, tomorrow, vol. 9, no. 1A, pp. 684-694, 2019.

[9] Yu. I. Popova, M. Magomedov, "Current status and development prospects of small and medium-sized enterprises", Econ.: yesterday, today, tomorrow, vol. 9, no. 1A, pp. 765-773, 2019.

[10] A.V. Gordeev et al., Food independence of Russia, In 2 volumes, vol. 2. Moscow: CD Technology, 2016, 604 p.

[11] L.P. Silaeva, "Placement and specialization of agricultural production in the EAEU as the basis for the formation of international cooperation", Fundam. and appl. Res. of the cooperat. sector of the econ., no. 3, pp. 59-65, 2018. 